\title{
Correction: Laboratory and numerical study of hyporheic flow-mediated DNAPL dissolution in karst conduits
}

\author{
Yuexia $\mathrm{Wu}^{1,2} \cdot$ Daniel Hunkeler $^{1} \cdot$ Nico Goldscheider $^{3}$
}

Published online: 21 September 2018

(C) Springer-Verlag GmbH Germany, part of Springer Nature 2018

\section{Correction: Hydrogeology Journal https://doi.org/10.1007/s10040-018-1858-3}

The original version of this article unfortunately contained a mistake. The spelling of the 3rd author's name was incorrect. The correct spelling is given above. The publisher regrets this mistake.

The original article has been corrected.

Yuexia $\mathrm{Wu}$

yxwu@niglas.ac.cn

1 Center for Hydrogeology and Geothermics (CHYN), University of Neuchâtel, Emile-Argand 11, CH-2000 Neuchâtel, Switzerland

2 Key Laboratory of Watershed Geographic Sciences, Nanjing Institute of Geography \& Limnology, Chinese Academy of Sciences, 73 East Beijing Road, 210008 Nanjing, People's Republic of China

3 Institute of Applied Geosciences, Division of Hydrogeology, Karlsruhe Institute of Technology (KIT), Kaiserstr. 12,

76131 Karlsruhe, Germany 